\title{
Biodegradation of endocrine disruptor Bisphenol A by Pseudomonas putida strain YC-AE1 isolated from polluted soil, Guangdong, China
}

Adel Eltoukhy ${ }^{1,2}$, Yang Jia ${ }^{1}$, Ruth Nahurira', M. A. Abo-Kadoum²,3, Ibatsam Khokhar', Junhuan Wang ${ }^{1}$ and Yanchun Yan $^{1 *}$

\begin{abstract}
Background: Bisphenol A is an important organic chemical as an intermediate, final and inert ingredient in manufacturing of many important products like polycarbonate plastics, epoxy resins, flame retardants, fooddrink packaging coating, and other. BPA is an endocrine disruptor compound that mimics the function of estrogen causing damage to reproductive organs. Bacterial degradation has been consider as a cost effective and eco-friendly method for BPA degradation compared with physical and chemical methods. This study aimed to isolate and identify bacterial strain capable to degrade and tolerate high concentrations of this pollutant, studying the factors affecting the degradation process and study the degradation mechanism of this strain.
\end{abstract}

Results: YC-AE1 is a Gram negative bacterial strain isolated from soil and identified as Pseudomonas putida by $16 \mathrm{~S}$ rRNA gene sequence and BIOLOG identification system. This strain found to have a high capacity to degrade the endocrine disruptor Bisphenol A (BPA). Response surface methodology using central composite design was used to statistically optimize the environmental factors during BPA degradation and the results obtained by significant model were $7.2,30^{\circ} \mathrm{C}$ and $2.5 \%$ for optimum initial $\mathrm{pH}$, temperature and inoculum size, respectively. Prolonged incubation period with low $\mathrm{NaCl}$ concentration improve the biodegradation of BPA. Analysis of variance (ANOVA) showed high coefficient of determination, $R^{2}$ and $A d j-R^{2}$ which were 0.9979 and 0.9935 , respectively. Substrate analysis found that, strain YC-AE1 could degrade a wide variety of bisphenol A-related pollutants such as bisphenol B, bisphenol F, bisphenol S, Dibutyl phthalate, Diethylhexyl phthalate and Diethyl phthalate in varying proportion. Pseudomonas putida YC-AE1 showed high ability to degrade a wide range of BPA concentrations $\left(0.5-1000 \mathrm{mg} \mathrm{I}^{-1}\right)$ with completely degradation for $500 \mathrm{mg} \mathrm{I}^{-1}$ within $72 \mathrm{~h}$. Metabolic intermediates detected in this study by HPLC-MS were identified as 4,4-dihydroxy-alpha-methylstilbene, $p$-hydroxybenzaldeyde, $p$-hydroxyacetophenone, 4hydroxyphenylacetate, 4-hydroxyphenacyl alcohol, 2,2-bis(4-hydroxyphenyl)-1-propanol, 1,2-bis(4-hydroxyphenyl)-2-propanol and 2,2-bis(4-hydroxyphenyl) propanoate.

Conclusions: This study reports Pseudomonas putida YC-AE1 as BPA biodegrader with high performance in degradation and tolerance to high BPA concentration. It exhibited strong degradation capacity and prominent adaptability towards a wide range of environmental conditions. Moreover, it degrades BPA in a short time via two different degradation pathways.

Keywords: Bisphenol A, Biodegradation, Pseudomonas putida, Endocrine disruptor, Degradation pathway, Response surface methodology

\footnotetext{
* Correspondence: yanyanchun@caas.cn

${ }^{1}$ Graduate School of Chinese Academy of Agricultural Sciences, Beijing

100081, China

Full list of author information is available at the end of the article
}

(c) The Author(s). 2020 Open Access This article is distributed under the terms of the Creative Commons Attribution 4.0 International License (http://creativecommons.org/licenses/by/4.0/), which permits unrestricted use, distribution, and reproduction in any medium, provided you give appropriate credit to the original author(s) and the source, provide a link to the Creative Commons license, and indicate if changes were made. The Creative Commons Public Domain Dedication waiver (http://creativecommons.org/publicdomain/zero/1.0/) applies to the data made available in this article, unless otherwise stated. 


\section{Background}

Xenobiotic endocrine disruptor compounds are environmental pollutants that have health and environmental harms, raising important concerns [1, 2]. Bisphenol A (BPA), 2,2-bis(4-hydroxyphenyl) propane is a well-known endocrine disruptor that is showing a highly estrogenic activity and acute toxicity [3]. It can bind to receptors for other hormonally mediated processes and cause endocrine disruptions. EPA and the U.S. Food and Drug Administration established a safe reference dose (RfD) for humans at $50 \mu \mathrm{g} / \mathrm{kg} /$ day [4]. Since hormones levels in the human body are present in biologically active concentrations, exposure to these exogenous chemicals even in low doses can disrupt the proper functioning of the body's endocrine system. In addition, dose scaling is valid for agents that follow linear dose-response relationships, many endocrine-disruptors, like their hormonal counterparts, demonstrate a nonmonotonic dose-response curve and in this case, lower doses are as relevant as higher doses [5-7]. Chemically, $\mathrm{BPA}$ is an organic compound consisting of two phenolic rings connected by a carbon bridge with two methyl group attached to this bridge [8].

The production of BPA has increased in the last few decades because of its widespread application in many industries [9] to reach the high global demand which was approximately 6.5 million tons in 2012 [10, 11]. BPA is used as a major component (as plasticizer) for various consumer products including detergents, phenol resins, epoxy resins, polycarbonates, polyesters, polyacrylates, plastic packing materials and lacquer coatings on food cans [11]. There are large number of studies that reported many damaging effects of BPA for both human and animal organs [12]. Detectable concentrations of BPA were reported in amniotic fluid, fetal circulation and placental tissue of pregnant women [13]. Many studies reported that, exposure of aquatic animals to BPA cause reproductive toxicity like changing in sex hormone level which affected the development of ovary in rare minnow Gobiocypris rarus [14], decreased sperm count, female biased sex ratio, and increased malformation and mortality in zebra fish [15]. BPA was detected in a wide range of environments including landfill leachates [16], industrial wastewater [17], source water and drinking water [18], rivers, seas, and soils [19-22]. Therefore, special attention has been given to BPA toxicity in these environments [23]. The most common methods to remove pollutants from the environment included photodegradation, photoelectrocatalytic oxidation, oxidation [17] and biodegradation [24]. Among all these methods, bacterial biodegradation of BPA was the most important one [25] because of low costs and less disruption of the contaminated environment when compared to other cleanup methods. Many researchers reported several BPA-degrading bacteria and their degrading performance Achromobacter xylosoxidans strain B-16 [25], Pseudomonas sp. and Pseudomonas putida strain [26], Bacillus megaterium Strain ISO-2 [27], Sphingomonas bisphenolicum strain AO1 [28] and Pseudomonas sp. and Sphingomonas sp. [10].

Microorganisms and their products are very important in industrial processes such as in synthesis of a number of products and fermentation processes. Their use is influenced by environmental factors such as a temperature, $\mathrm{pH}$, nutrients and as must be prior optimized before application. The optimization by one factor at time (OFAT) involves changing in one factor while other factors or variables at certain levels are fixed [29]. This method of optimization is time consuming especially with large number of variables in addition to, ignoring the interactions between different variables. These disadvantages of singlefactor experiments can be overcome by using statistical optimization which allows all interactions of all variables and levels [30, 31].

In this study, a highly BPA tolerant strain with high BPA biodegradation capacity was isolated from soil sample beside the electronic wastes collection area in Guangdong province, China and identified as Pseudomonas putida YC-AE1, the environmental conditions affecting BPA degradation were studied using statistical methods and discussed. The ability of strain YC-AE1 to degrade other pollutants related to BPA was also studied. The metabolic intermediate compounds detected during the biodegradation process were identified and biodegradation pathways were proposed.

\section{Results}

Isolation and identification of BPA degrading strain

YC-AE1 strain isolated from the soil sample of Guangdong province showed high degradation and tolerance to BPA. It is a rod-shaped, flagellated, Gram-negative bacterium. The amplified $16 \mathrm{~S}$ rRNA gene sequence (1439 bp) was deposited in Gen Bank (accession number, MK318658) and related strains were obtained by BLAST. The similarity between YC-AE1 and others was detected by constructing a phylogenetic tree (Fig.1) and the most closely related one was Pseudomonas putida strain W30 with 99\% similarity. The BIOLOG tests was performed and showed consistent results with the $16 \mathrm{~S}$ rRNA gene $(\mathrm{PROB}=97.2 \%, \mathrm{SIM}=0.849$, and $\mathrm{DIST}=$ 1.818 with Pseudomonas putida). According to morphology, BIOLOG tests and 16S rRNA gene sequencing, our strain YC-AE1 identified as Pseudomonas putida.

\section{Statistical optimization of BPA degradation using RSM}

The combined five factors with their levels and obtained experimental results are presented in Table 1, the highest BPA degradation (95\%) was observed in the result obtained by the design (run No. 21). The design was 
(a)

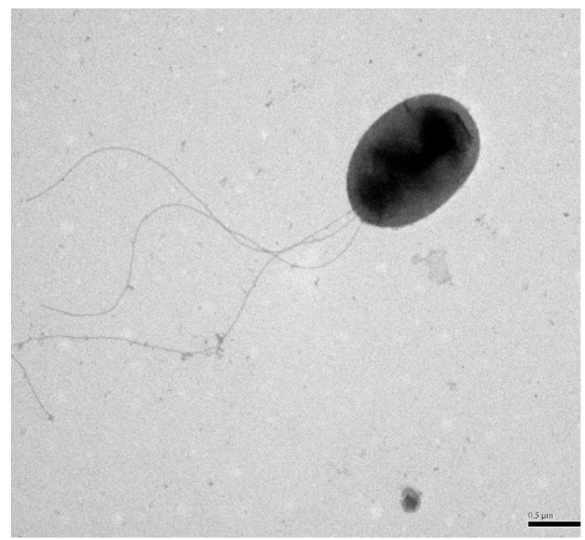

Fig. 1 Identification of YC-AE1, (a) TEM investigation showing cell shape and lophotrichous flaggelation (b) amplified 16S rRNA gene (about 1500 bp) comparing with 2000 bp DNA ladder, (c) phylogenetic tree of Pseudomonas putida YC-AE1 with closely related strains (b)

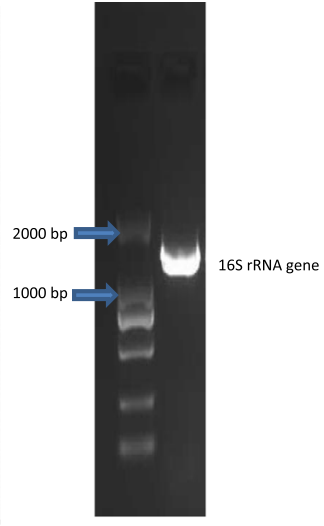

(c)

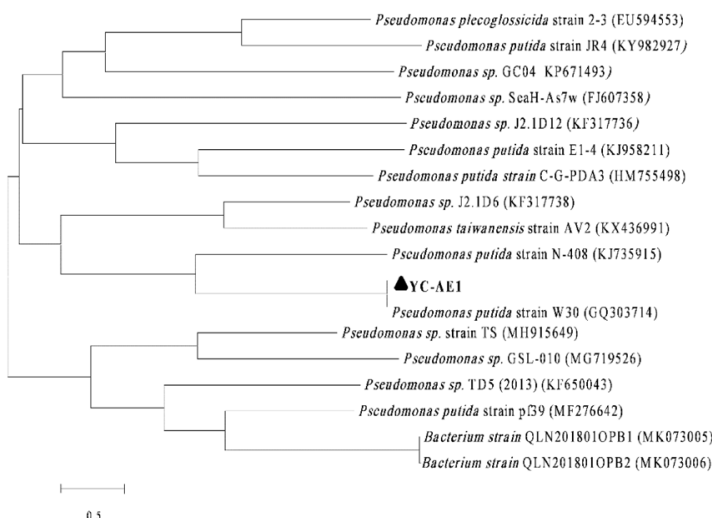

05 analyzed by regression analysis resulted in a significant model with the following regression equation:

$B P A$ degradation $=77.93957+14.45 A-12.65 B+22 C+11.425 D-4.45 E+$ $1.38625 A B-1.48625 A E-2.71125 B D+17.65125 B E-11.9997 A^{2}-3.59973 B^{2}-$ $8.27473 C^{2}-9.68723 D^{2}-17.5497 E^{2}-7.42375 A^{2} B-21.6013 A^{2} C-8.23875 A^{2} D$ $18.7013 A^{2} E-13.8863 A B^{2}$

where, A, B, C, D and E are the actual values of initial $\mathrm{pH}, \mathrm{NaCl}$ concentration, incubation period, inoculum size and Incubation temperature, respectively. Regression analysis for the biodegradation shown in Table 2, indicate that the model used in our study was highly significant with very low $P$-value $(0.0001)$ and high F-value (229.53). As shown in Table 2, all linear and quadratic variables were highly significant with $p$-value close to (0.00) indicating the model success. Two of variable interactions; $\mathrm{pH}$ and $\mathrm{NaCl}$ concentration $(\mathrm{AB})$ and $\mathrm{pH}$ and incubation temperature (AE) were slightly nonsignificant with $p$-values 0.0944 and 0.0760 respectively, indicating the interactions were not favorable to the response while, the other two variables, $\mathrm{NaCl}$ concentration and inoculum size (BD) and $\mathrm{NaCl}$ concentration and incubation temperature (BE) were highly significant. The model fitness was expressed by the coefficient of determination, $\mathrm{R}^{2}$ and $\mathrm{Adj}-\mathrm{R}^{2}$ which were 0.9979 and 0.9935 , respectively.

To determine the optimum values of BPA degradation conditions for obtaining the highest and fastest degradation rate, three-dimensional (3-D) response surface curves were plotted as shown in Fig. 2. These results showed that an optimum was observed near the central value of $\mathrm{pH}$, temperature and inoculum size. Pseudomonas putida YC-AE1 could grow and degrade BPA over a wide range of $\mathrm{pH}$ values with optimum value 7.2 , Fig. 2a-d. The biodegradation of BPA was highly affected by the incubation period, it can be easily observed this effect from the high positive coefficient value $(+22)$ of the variable as shown in Table 2. From Fig. 2a, prolonged incubation period was shown to increase the degradation of BPA by our strain $\mathrm{YC}-\mathrm{AE} 1$.

The effect of temperature on BPA degradation by YCAE1 showed in Fig. 2d. There was a gradual increase in BPA degradation by $\mathrm{YC}-\mathrm{AE} 1$ by increasing the temperature from 15 to $25^{\circ} \mathrm{C}$ and the maximum degradation was observed between 25 and $30^{\circ} \mathrm{C}$. The degradation then decreased beyond increasing temperature degrees. As shown in Table 2 the addition of $\mathrm{NaCl}$ to the degradation medium (TEM) has a reverse effect on BPA degradation, as described by a negative coefficient value (-12). Data illustrated in Fig. $2 \mathrm{~b}$, e, f showed a sever decrease in BPA degradation by YC-AE1 with increasing $\mathrm{NaCl}$ concentration. The optimum inoculum size for BPA degradation was $2.5 \%$ and this can be clearly observed in the data plotted in Fig. 2c, e.

\section{Substrate utilization test}

The capability of Pseudomonas putida strain YC-AE1 to degrade six different organic pollutants (BPB, BPF, BPS, DBP, DEP and DEHP) was examined. Data presented in Fig. 3 showed that, the YC-AE1 has an ability to degrade all examined pollutants in varying proportions. Pseudomonas putida YC-AE1 showed high ability to degrade about 60 and $67 \%$ of bisphenol B and $F\left(100 \mathrm{mg} \mathrm{l}^{-1}\right)$, respectively, while lower degradation was observed in both bisphenol S, DBP and DEHP with about 30, 20 and 18\% respectively.

\section{High and low BPA concentration for efficient biodegradation}

The degradation rates in low and high BPA concentration are demonstrated in Fig. 4a, b after 15 and $72 \mathrm{~h}$ 
Table 1 Experimental design (conditions and responses) for BPA degradation by Pseudomonas putida YC-AE1

\begin{tabular}{|c|c|c|c|c|c|c|}
\hline \multirow{2}{*}{$\begin{array}{l}\text { Run } \\
\text { No. }\end{array}$} & \multirow{2}{*}{$\begin{array}{l}\text { A } \\
\text { Initial pH (values) }\end{array}$} & \multirow{2}{*}{$\begin{array}{l}\mathrm{B} \\
\mathrm{NaCl} \text { Conc. (\%) }\end{array}$} & \multirow{2}{*}{$\begin{array}{l}\text { C } \\
\text { Incubation period (hours) }\end{array}$} & \multirow{2}{*}{$\begin{array}{l}\text { D } \\
\text { Inoculum size (\%) }\end{array}$} & \multirow{2}{*}{$\begin{array}{l}\text { E } \\
\text { Incubation temp. }\left({ }^{\circ} \mathrm{C}\right)\end{array}$} & \multirow{2}{*}{$\begin{array}{l}\text { BPA } \\
\text { degradation } \\
(\%)^{\mathrm{a}}\end{array}$} \\
\hline & & & & & & \\
\hline 7 & $5.00(-2)$ & $0.75(0)$ & $20(0)$ & $2.5(0)$ & $31(0)$ & 2.2 \\
\hline 5 & $6.13(-1)$ & $1.13(+1)$ & $15(-1)$ & $3.25(+1)$ & $37(+1)$ & 2.7 \\
\hline 8 & $6.13(-1)$ & $1.13(+1)$ & $15(-1)$ & $1.75(-1)$ & $25(-1)$ & 7.8 \\
\hline 10 & $6.13(-1)$ & $0.38(-1)$ & $25(+1)$ & $1.75(-1)$ & $25(-1)$ & 81.7 \\
\hline 11 & $6.13(-1)$ & $1.13(+1)$ & $25(+1)$ & $1.75(-1)$ & $37(+1)$ & 0 \\
\hline 12 & $6.13(-1)$ & $0.38(-1)$ & $15(-1)$ & $1.75(-1)$ & $37(+1)$ & 0 \\
\hline 14 & $6.13(-1)$ & $1.13(+1)$ & $25(+1)$ & $3.25(+1)$ & $25(-1)$ & 6.4 \\
\hline 28 & $6.13(-1)$ & $0.38(-1)$ & $25(+1)$ & $3.25(+1)$ & $37(+1)$ & 13.38 \\
\hline 29 & $6.13(-1)$ & $0.38(-1)$ & $15(-1)$ & $3.25(+1)$ & $25(-1)$ & 93.5 \\
\hline 1 & $7.25(0)$ & $0.75(0)$ & $10(-2)$ & $2.5(0)$ & $31(0)$ & 2 \\
\hline 2 & $7.25(0)$ & $1.5(+2)$ & $20(0)$ & $2.5(0)$ & $31(0)$ & 39.4 \\
\hline 3 & $7.25(0)$ & $0.75(0)$ & $20(0)$ & $2.5(0)$ & $31(0)$ & 77 \\
\hline 4 & $7.25(0)$ & $0.75(0)$ & $20(0)$ & $2.5(0)$ & $19(-2)$ & 17.8 \\
\hline 15 & $7.25(0)$ & $0.75(0)$ & $20(0)$ & $2.5(0)$ & $31(0)$ & 77.2 \\
\hline 16 & $7.25(0)$ & $0.75(0)$ & $30(+2)$ & $2.5(0)$ & $31(0)$ & 90 \\
\hline 19 & $7.25(0)$ & $0.75(0)$ & $20(0)$ & $4(+2)$ & $31(0)$ & 63.2 \\
\hline 20 & $7.25(0)$ & $0(-2)$ & $20(0)$ & $2.5(0)$ & $31(0)$ & 90 \\
\hline 22 & $7.25(0)$ & $0.75(0)$ & $20(0)$ & $2.5(0)$ & $31(0)$ & 77.3 \\
\hline 23 & $7.25(0)$ & $0.75(0)$ & $20(0)$ & $2.5(0)$ & $43(+2)$ & 0 \\
\hline 24 & $7.25(0)$ & $0.75(0)$ & $20(0)$ & $1(-2)$ & $31(0)$ & 17.5 \\
\hline 6 & $8.38(+1)$ & $0.38(-1)$ & $25(+1)$ & $1.75(-1)$ & $37(+1)$ & 1.7 \\
\hline 9 & $8.38(+1)$ & $1.13(+1)$ & $15(-1)$ & $3.25(+1)$ & $25(-1)$ & 17.5 \\
\hline 13 & $8.38(+1)$ & $1.13(+1)$ & $25(+1)$ & $1.75(-1)$ & $25(-1)$ & 15 \\
\hline 18 & $8.38(+1)$ & $0.38(-1)$ & $15(-1)$ & $3.25(+1)$ & $37(+1)$ & 7 \\
\hline 21 & $8.38(+1)$ & $0.38(-1)$ & $25(+1)$ & $3.25(+1)$ & $25(-1)$ & 95 \\
\hline 25 & $8.38(+1)$ & $1.13(+1)$ & $15(-1)$ & $1.75(-1)$ & $37(+1)$ & 0 \\
\hline 26 & $8.38(+1)$ & $1.13(+1)$ & $25(+1)$ & $3.25(+1)$ & $37(+1)$ & 0 \\
\hline 27 & $8.38(+1)$ & $0.38(-1)$ & $15(-1)$ & $1.75(-1)$ & $25(-1)$ & 78.3 \\
\hline 17 & $9.5(+2)$ & $0.75(0)$ & $20(0)$ & $2.5(0)$ & $31(0)$ & 60 \\
\hline
\end{tabular}

${ }^{\mathrm{a}}$ All response (BPA degradation percentage) values are shown as means for three independent experiments

cultivation, respectively. As shown in Fig. 4a, the strain was able to degrade more than $80 \%$ of $0.5 \mathrm{mgl}^{-1} \mathrm{BPA}$ then, the degradation gradually increased with increasing the concentration to reach $100 \%$ with 10 and $12 \mathrm{mgl}^{-}$in that short incubation time $(15 \mathrm{~h})$. On the other hand of high concentrations (Fig. 4b, the strain YC-AE1 was able to degrade $100 \%$ of BPA (50-500 $\left.\mathrm{mg} \mathrm{l}^{-1}\right)$. However, when the BPA concentration increased $(600,700,800$, 900 and $1000 \mathrm{mg} \mathrm{l}^{-1}$ ) the degradation rate decreased to $(95,90,70,60$ and $7 \%)$, respectively. Further incubation of strain YC-AE1 for another 2 days resulted in complete degradation of BPA (600-1000 $\left.\mathrm{mg} \mathrm{l}^{-1}\right)$. For detection of BPA mineralization, TOC experiment was performed, and the data obtained illustrated in Fig. 5. There was a dramatical significant decreasing in TOC starting from 78 to $20 \mathrm{mg} \mathrm{l}^{-1}$ after 0 and $32 \mathrm{~h}$ incubation, respectively, (i.e., 75\% depletion in TOC). With the degradation time further going on, there was nonsignificant decreasing in TOC to reach finally $82 \%$ at 64 $\mathrm{h}$ incubation.

Metabolic intermediates and metabolic pathway

Detection of metabolic intermediates during BPA degradation with optimum conditions (200 $\mathrm{mgl}^{-1} \mathrm{BPA}, \mathrm{pH} 7.2$, $30{ }^{\circ} \mathrm{C}$ and $2.5 \%$ inoculum size) was performed. Based on the mass spectra (LC-MS) as shown in Fig. 6, eight compounds relating to BPA degradation were identified as following, BPA (m/z 227.1), 4,4-Dihydroxy-alpha-methylstilbene (m/z 225), $p$-hydroxybenzaldeyde ( $p$-HBAL) (m/z 122), $p$-hydroxyacetophenone ( $p$-HAP) $(\mathrm{m} / \mathrm{z}$ 136), 4-hydroxyphenylacetate 
Table 2 Regression analysis for the biodegradation of BPA by Pseudomonas putida YC-AE1

\begin{tabular}{|c|c|c|c|c|c|c|}
\hline Source & Coefficient & Sum of Squares & Degrees of freedom & Mean Square & F Value & $\begin{array}{l}P \text { value } \\
\text { Prob }>F\end{array}$ \\
\hline Model & & $38,370.26$ & 19 & 2019.48 & 229.53 & $<0.0001$ \\
\hline $\mathrm{pH}, \mathrm{A}$ & 14.45 & 1670.42 & 1 & 1670.42 & 189.86 & $<0.0001$ \\
\hline $\mathrm{NaCl}$ Conc., B & -12.65 & 1280.18 & 1 & 1280.18 & 145.50 & $<0.0001$ \\
\hline Incubation period, $\mathrm{C}$ & 22 & 3872 & 1 & 3872 & 440.09 & $<0.0001$ \\
\hline Inoculum size, D & 11.425 & 1044.24 & 1 & 1044.24 & 118.68 & $<0.0001$ \\
\hline Incubation temp., E & -4.45 & 158.42 & 1 & 158.42 & 18.00 & 0.0022 \\
\hline$A B$ & 1.38625 & 30.74 & 1 & 30.74 & 3.49 & 0.0944 \\
\hline$A E$ & -1.48625 & 35.34 & 1 & 35.34 & 4.01 & 0.0760 \\
\hline $\mathrm{BD}$ & -2.71125 & 117.61 & 1 & 117.61 & 13.36 & 0.0053 \\
\hline BE & 17.65125 & 4985.06 & 1 & 4985.06 & 566.60 & $<0.0001$ \\
\hline$A^{2}$ & -11.9997 & 3532.64 & 1 & 3532.64 & 401.52 & $<0.0001$ \\
\hline$B^{2}$ & -3.59973 & 317.90 & 1 & 317.90 & 36.13 & 0.0002 \\
\hline$C^{2}$ & -8.27473 & 1679.82 & 1 & 1679.82 & 190.92 & $<0.0001$ \\
\hline$D^{2}$ & -9.68723 & 2302.26 & 1 & 2302.26 & 261.67 & $<0.0001$ \\
\hline$E^{2}$ & -17.5497 & 7556.09 & 1 & 7556.09 & 858.82 & $<0.0001$ \\
\hline$A^{2} B$ & -7.42375 & 293.93 & 1 & 293.93 & 33.40 & 0.0003 \\
\hline$A^{2} C$ & -21.6013 & 2488.60 & 1 & 2488.60 & 282.85 & $<0.0001$ \\
\hline$A^{2} D$ & -8.23875 & 362.01 & 1 & 362.01 & 41.14 & 0.0001 \\
\hline$A^{2} E$ & -18.7013 & 1865.26 & 1 & 1865.26 & 212.00 & $<0.0001$ \\
\hline$A B^{2}$ & -13.8863 & 1028.41 & 1 & 1028.41 & 116.89 & $<0.0001$ \\
\hline Residual & & 79.18 & 9 & 8.79 & & \\
\hline Lack of Fit & & 79.13 & 7 & 11.30 & 484.50 & 0.0021 \\
\hline Pure Error & & 0.04 & 2 & 0.02 & & \\
\hline Total & & $38,449.44$ & 28 & $R^{2}=0.9979$ & $\operatorname{Adj}-R^{2}=0.9935$ & \\
\hline
\end{tabular}

(HPA) and 4-Hydroxyphenacylalcohol (same m/z, 152), 2,2bis(4-hydroxyphenyl)-1-propanol and 1,2-bis (4-hydroxyphenyl)-2-propanol (same $\mathrm{m} / \mathrm{z}, 244$ ) and 2,2-bis (4-hydroxyphenyl) propanoate $(\mathrm{m} / \mathrm{z} 258)$. Based on the intermediates obtained during the biodegradation of BPA, the proposed pathway for BPA biodegradation by strain YC-AE1 is represented in Fig. 7. There were two different proposed pathways for BPA degradation by YC-AE1, both of them start by hydroxylation for BPA to form 1,2-Bis(4-hydroxyphenyl)-2-propanol and 2,2-Bis(4-hydroxyphenyl)-1-propanol in pathway (I) and (II), respectively. In pathway (I), 1,2-Bis(4-hydroxyphenyl)-2-propanol dehydrated to 4,4-Dihydroxy-alpha-methylstilbene [32]. The previously mentioned compound was further oxidized to form $p$ - HBAL and $p$ - HAP. $p$ - HAP was metabolized to HPA and then to HQ. Both of hydroxybenzoic acid (HBA) and HQ were assumed mineralized to carbon dioxide $\left(\mathrm{CO}_{2}\right)$ and bacterial biomass through benzoate degradation pathway. HBA and HQ were not detected and presumed in the pathway. In pathway (II), 2,2-Bis(4-hydroxyphenyl)-1-propanol is metabolized to form 2,2-bis (4-hydroxyphenyl) propanoate and 2,3-Bis(4-hydroxyphenyl)-1,2propanediol. The intermediate (2, 3-Bis (4-hydroxyphenyl)-1, 2-propanediol) was further metabolized through many steps (as shown in Fig. 7) to form finally HBA which mineralized to $\mathrm{CO}_{2}$ and bacterial biomass through benzoate degradation pathway.

\section{Discussion}

There currently is increasing interest in endocrine disruptors, and their biodegradation by bacteria has been extensively studied. BPA is a known endocrine disruptor that displays estrogenic activity and acute toxicity [3]. Finding new bacterial strains with strong degradation capacity and prominent adaptability towards a wide range of environmental conditions is of great importance. In our study, one bacterial strain showed excellent biodegradation performance was isolated and identified as Pseudomonas putida strain YC-AE1 according to identification methods. YC-AE1 could degrade $200 \mathrm{mgl}^{-1}$ within $20 \mathrm{~h}$ under optimum environmental factors. For optimizing the factors affecting the biodegradation process, RSM was performed using CCD. RSM is used to determine the combined effect of several variables and their interactions. A statistical optimization approach using CCD was used 
(a)

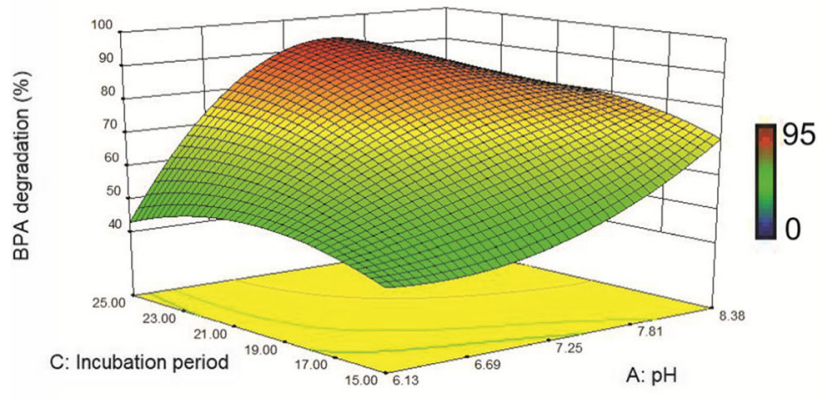

(c)

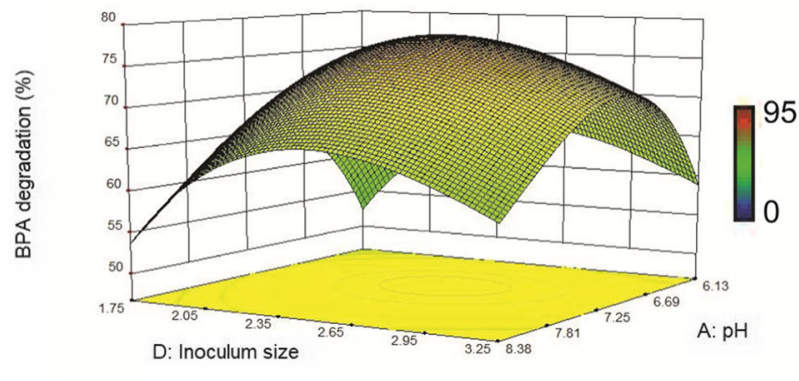

(e)

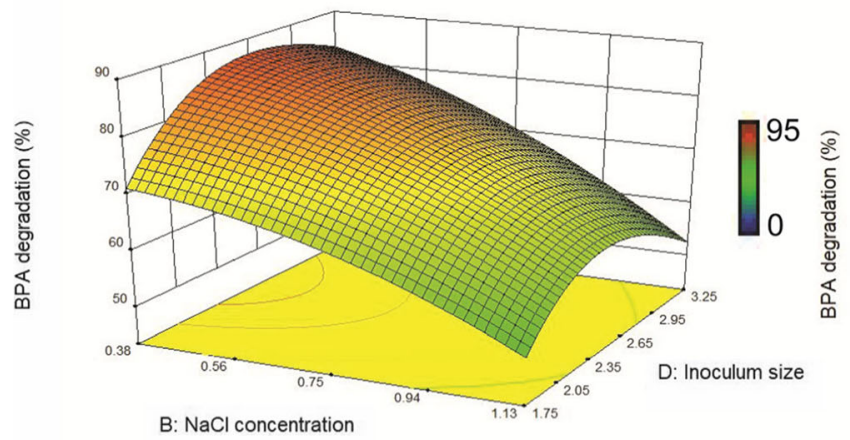

(b)

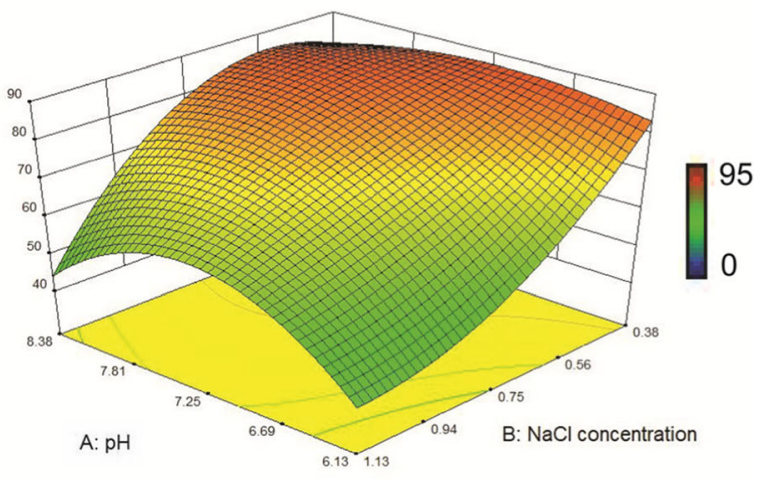

(d)

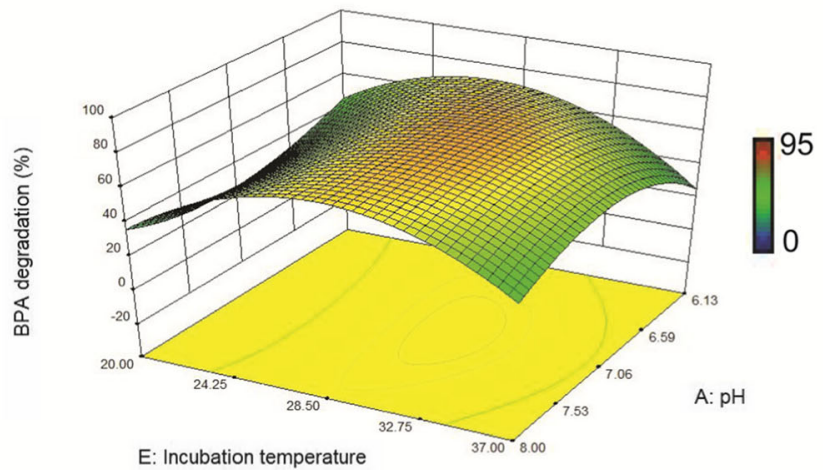

(f)

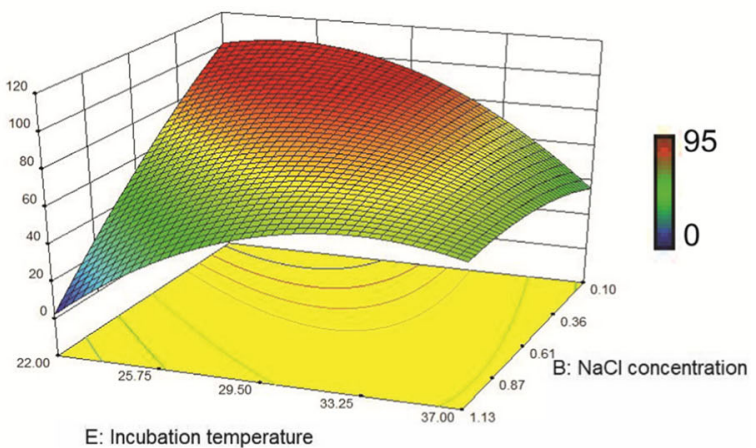

Fig. 2 Response surface plots showing the effect of incubation period and $\mathrm{pH}(\mathbf{a}) ; \mathrm{pH}$ and $\mathrm{NaCl}$ concentration (b); inoculum size and pH (c); incubation temperature and $\mathrm{pH}$ (d); $\mathrm{NaCl}$ concentration and inoculum size (e); incubation temperature and $\mathrm{NaCl}(\mathbf{f})$

to study the linear, quadratic and interactive effects of various parameters on BPA degradation by Pseudomonas putida strain YC-AE1. The F-value and probability value ( $p$-value) are tools for evaluating the significance of each of the parameters in the model equation. The pattern of interactions between the variables is indicated by these coefficients. The larger Fvalue and the smaller $P$-value are an indication of the high significance of the corresponding coefficient [30]. The high value of $R^{2}$ (so close to 1 ) supports the accuracy of the model and demonstrates a good correlation between actual and predicted values of BPA degradation. The significance of the model and high $R^{2}$, support the model to predict responses. For microbial effective process, it is necessary to monitor and control parameters that affect the process like, inoculum volume, salt concentration, $\mathrm{pH}$, temperature, incubation period, etc. Maximum BPA degradation was observed at $\mathrm{pH}$ of 7.2 and our results was different from that obtained by $[25,33]$ which reported that maximum BPA degradation was shown at $\mathrm{pH} 7$ by Achromobacter xylosoxidans strain B-16 and Arthrobacter sp. YC-RL1. 


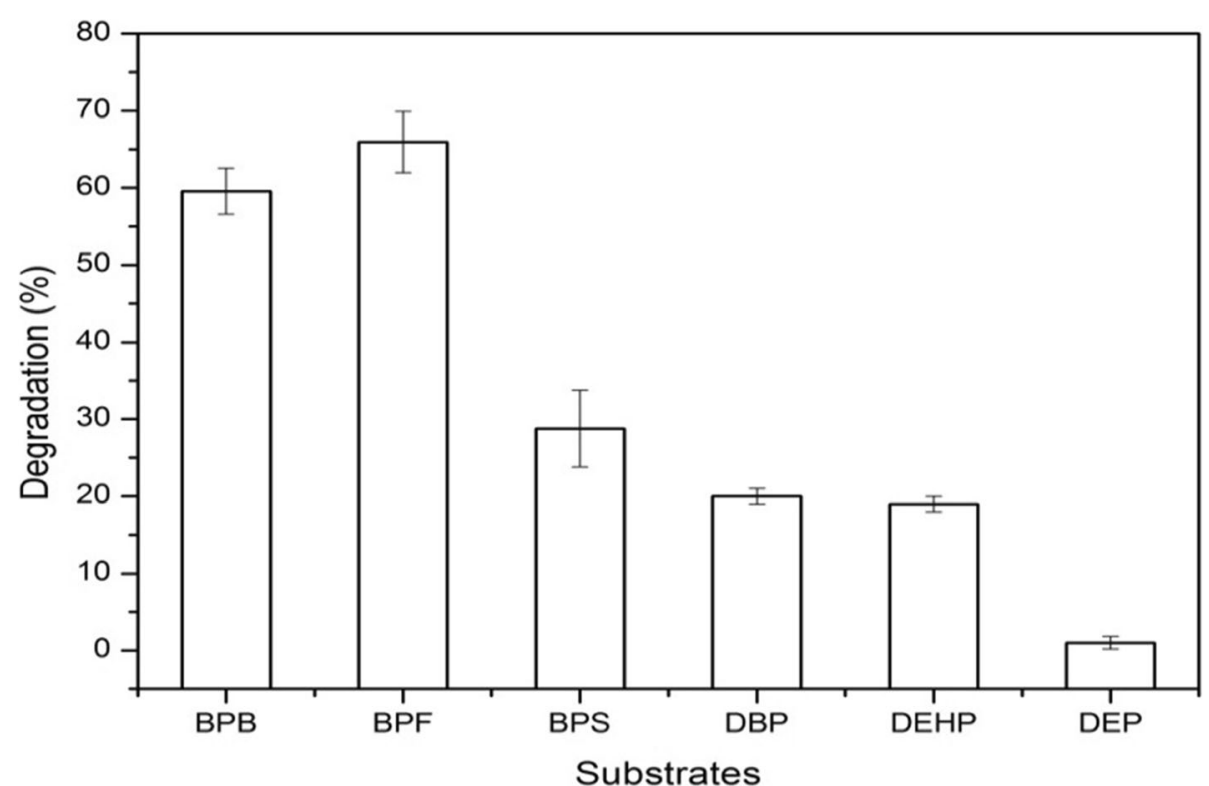

Fig. 3 Degradation efficiency for different pollutants $\left(100 \mathrm{mg} \mathrm{I}^{-1}\right)$ by Pseudomonas putida YC-AE1. Error bars indicate the standard deviation obtained in three independent experiments

The inoculums to be used in degradation medium must be in a healthy and active state moreover being of optimum size. Such conditions possibly minimize the length of the log phase. Lower inoculum volumes decrease the degradation efficiency of YC-AE1 and, this is may be due to low number of bacterial cells that decrease the amount of enzymes for biodegradation. Also, inoculum size higher than the optimum value (2.5\%) had a little increasing effect on BPA degradation by YC-AE1, and this may be because the reduction of dissolved oxygen and increased competition towards nutrients [34].
Zhang et al. [25] reported that, increasing the size of inoculum leads to increase the degradation of BPA by Achromobacter xylosoxidans strain B-16 isolated from compost leachate of municipal solid waste.

Temperature is one of the most important parameters that affect any microbial process. The growth rate of microorganisms becomes slow below or above the optimum growth temperature because of a reduced rate of cellular production [35]. Enzyme thermal stability and activity is correlated to an organism's growth temperature and also, degradation is an enzyme-controlled activity hence as the

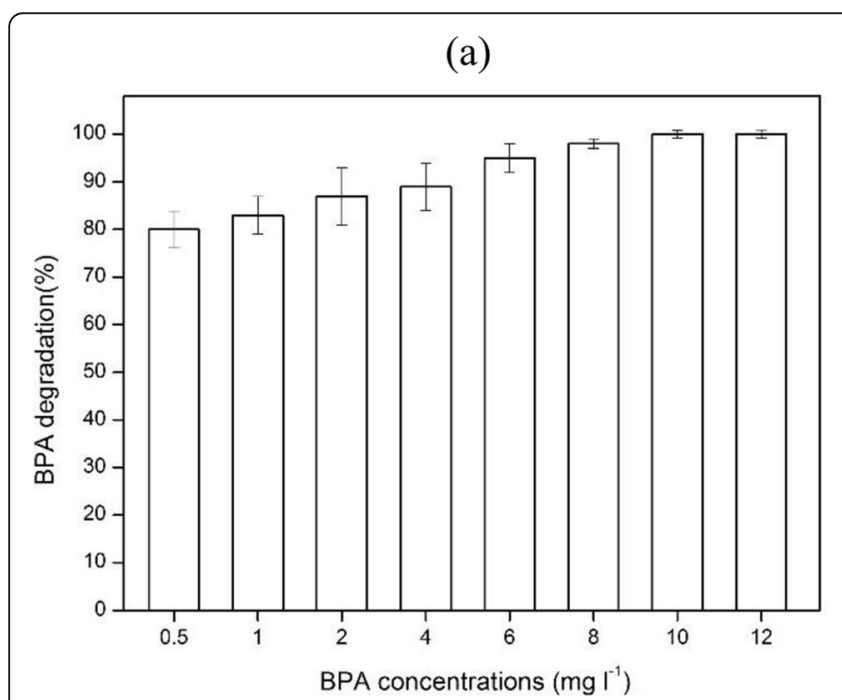

(b)

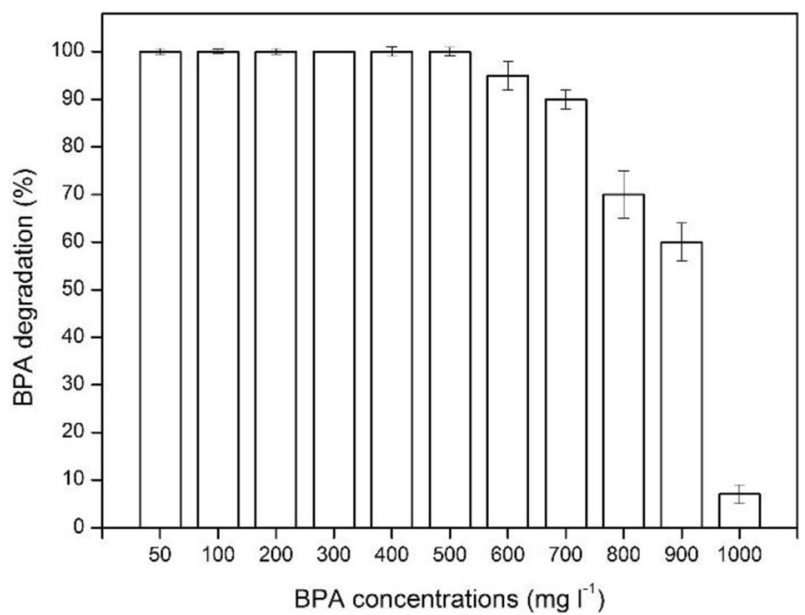

Fig. 4 Ability of Pseudoonas putida YC-AE1 to degrade Low (a) and High (b) BPA concentrations. Error bars indicate the standard deviation obtained in three independent experiments 


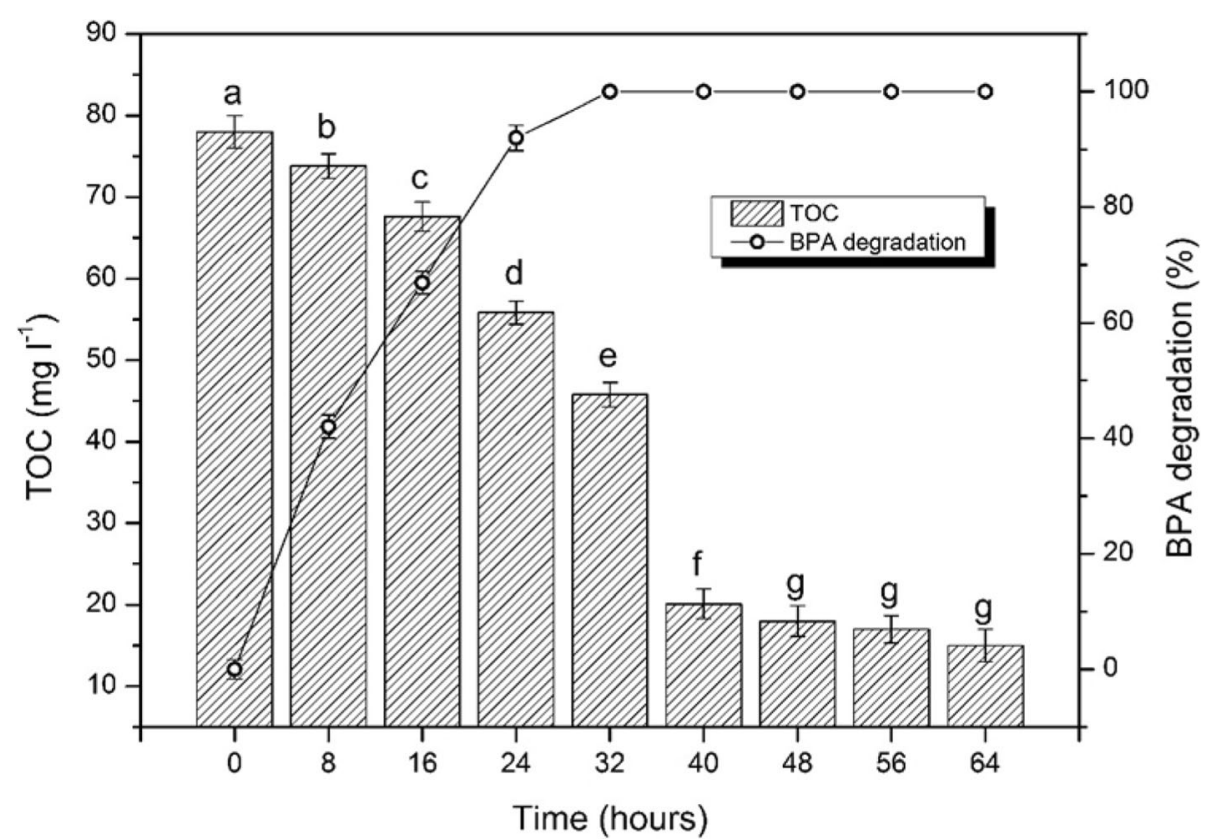

Fig. 5 Total organic carbon depletion and BPA degradation by Pseudomonas putida YC-AE1. The different letters represent significant differences at $P \leq 0.05$

temperature increases, the cellular growth and physiological functions increase to an optimum value [36]. Fouda [37] reported a relatively high optimum temperature (35$40^{\circ} \mathrm{C}$ ) for BPA biodegradation by Klebsiella pneumoniae $\mathrm{J} 2$ and Enterobacter asburiae L4. The biodegradation of $\mathrm{BPA}$ was greatly reduced by addition of $\mathrm{NaCl}$ to the medium component and this result may be due to the effect of $\mathrm{NaCl}$ on the growth curve of our strain by elongating the lag phase and delaying the degradation process $[38,39]$ and this explains why the strain regains its ability to degrade BPA in the presence of salt by further incubation for another 2 days resulted in degradation of $70 \%$ of BPA (Data not shown).

It is very important for bacterial strain intended to use in natural remediation to has ability to degrade many pollutants or at least many derivatives of one pollutant. For that purpose, our strain Pseudomonas putida YCAE1 was examined to degrade and tolerate 6 different BPA-related organic pollutants. BPS was the hardest one in the examined bisphenols to degrade because it contains $\mathrm{S}=\mathrm{O}$ double chemical bond, which gives the structure chemical durability. The steric effects between the substrates and the responsible enzymes declines from $\mathrm{BPB}$ to BPF, which may be the reason why BPF is easier to degrade. The lowest degradation ability was shown with DEP with degradation rate not more than $3 \%$. Many Pollutants were reported to be degraded by Pseudomonas $s p$ by researchers. For example, phenols [40], phenolics like pentachlorophenol [41] and Catechol [42]. Under normal environmental conditions, the concentration of environmental pollutants is always very low compared with that examined in vitro $[43,44]$ and these pose many problems for bioremediation process because, the concentration of pollutants is too low to sustain microbial growth and ensure the accessibility to microbe and even more than that to induce metabolic genes [33]. Therefore, determining the survival ability of Pseudomonas putida YC-AE1 against both high and low BPA concentrations is important. Strain YC-AE1 could survive in both conditions and remain active in all BPA concentrations. This performance and ability of strain YC-AE1 to degrade and tolerate these extremely low and high concentrations are important for application in BPA bioremediation especially with fast degradation rate $\left(200 \mathrm{mgl}^{-1}\right.$ in $\left.20 \mathrm{~h}\right)$. This quality makes strain YC-AE1 a promising bacterium compared with other reported strains. Suyamud et al. [27] reported Bacillus megaterium strain ISO-2, which can degrade $5 \mathrm{mgl}^{-1}$ of BPA within $72 \mathrm{~h}$ on mineral salt medium supplemented with yeast extract as co-substrate. Sphingomonas bisphenolicum strain AO1 was reported to degrade $100 \mathrm{mgl}^{-1}$ $\mathrm{BPA}$ to undetectable level within $48 \mathrm{~h}$ in minimum medium with $1 \%$ glucose [28].

Biodegradation of BPA and its metabolic intermediates could not fully support the mineralization of BPA, TOC experiment could show the mineralization rate of BPA. Although, faster BPA mineralization rate has generally been reported for microbial communities than the culture of BPA-degrading lonely strains [45], interestingly, our strain Pseudomonas putida YC-AE1 lonely demonstrated 

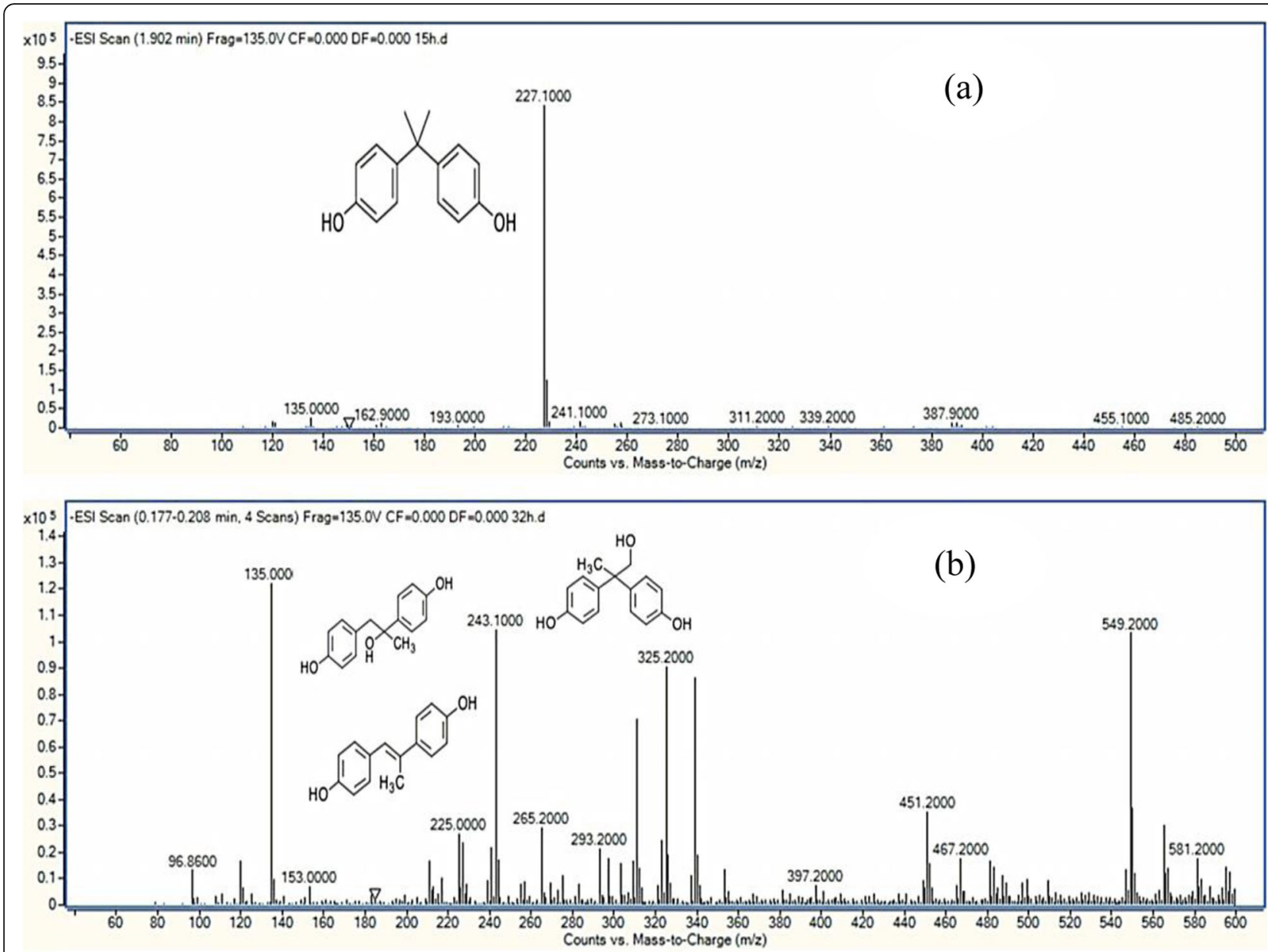

$\times 10^{5}$. ESI SCan (1.578 min) Frag= $135.0 \mathrm{~V}$ CF $=0.000 \mathrm{DF}=0.00036 \mathrm{h.d}$

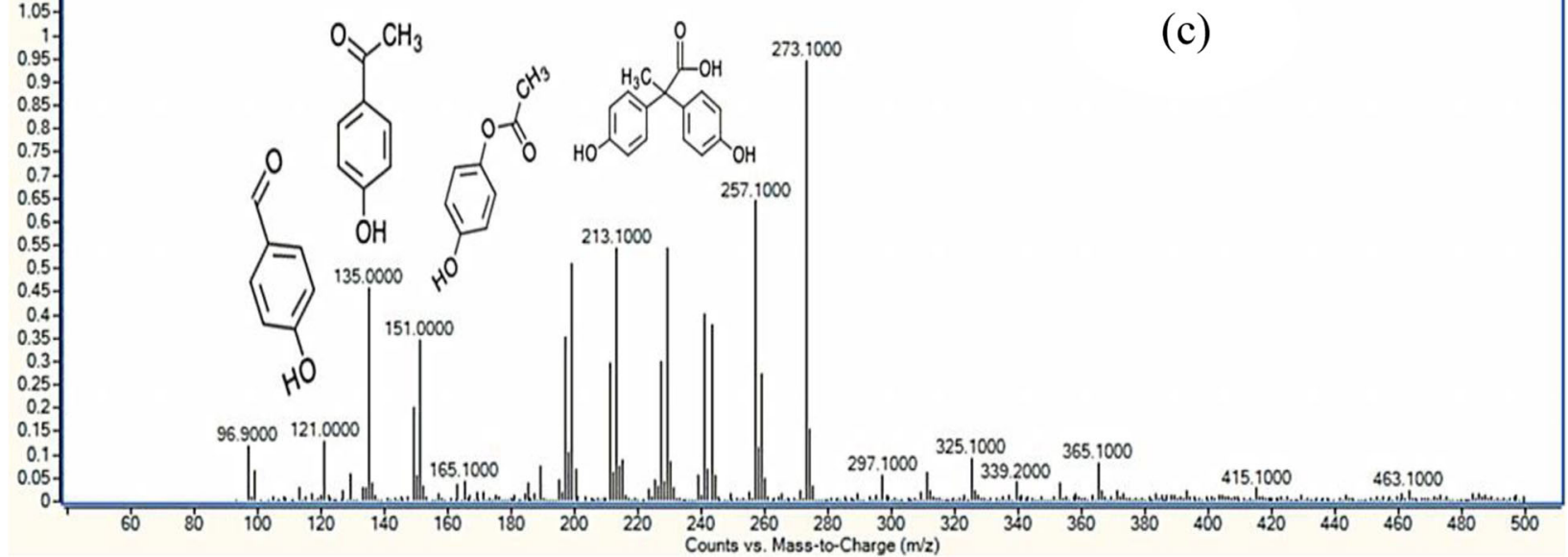

Fig. 6 Mass spectra from HPLC-MS during BPA degradation by Pseudomonas putida YC-AE1 and detected intermediate compounds, BPA (a), 4,4Dihydroxy-alpha-methylstilbene, 1,2-bis (4-hydroxyphenyl)-2-propanol and 2,2-bis(4-hydroxyphenyl)-1-propanol (b), 2,2-bis (4-hydroxyphenyl) propanoate, $p$-HBAL, p-HAP and HPA (c)

high BPA mineralization compared with microbial communities. Although, the TOC depletion percentage in our experiment (82\% after $64 \mathrm{~h}$ ) by Pseudomonas putida YCAE1 was closely similar to that reported by Yu et al. [45] that used co-culture of sphingomonas sp. (Sph-2) and Pseudomonas sp. (84\% after $72 \mathrm{~h}$ ), Surprisingly, our experiment was conducted with $100 \mathrm{mgl}^{-1}$ compared with $50 \mathrm{mgl}^{-1}$ BPA by Yu et al. [45], and these results reflect 


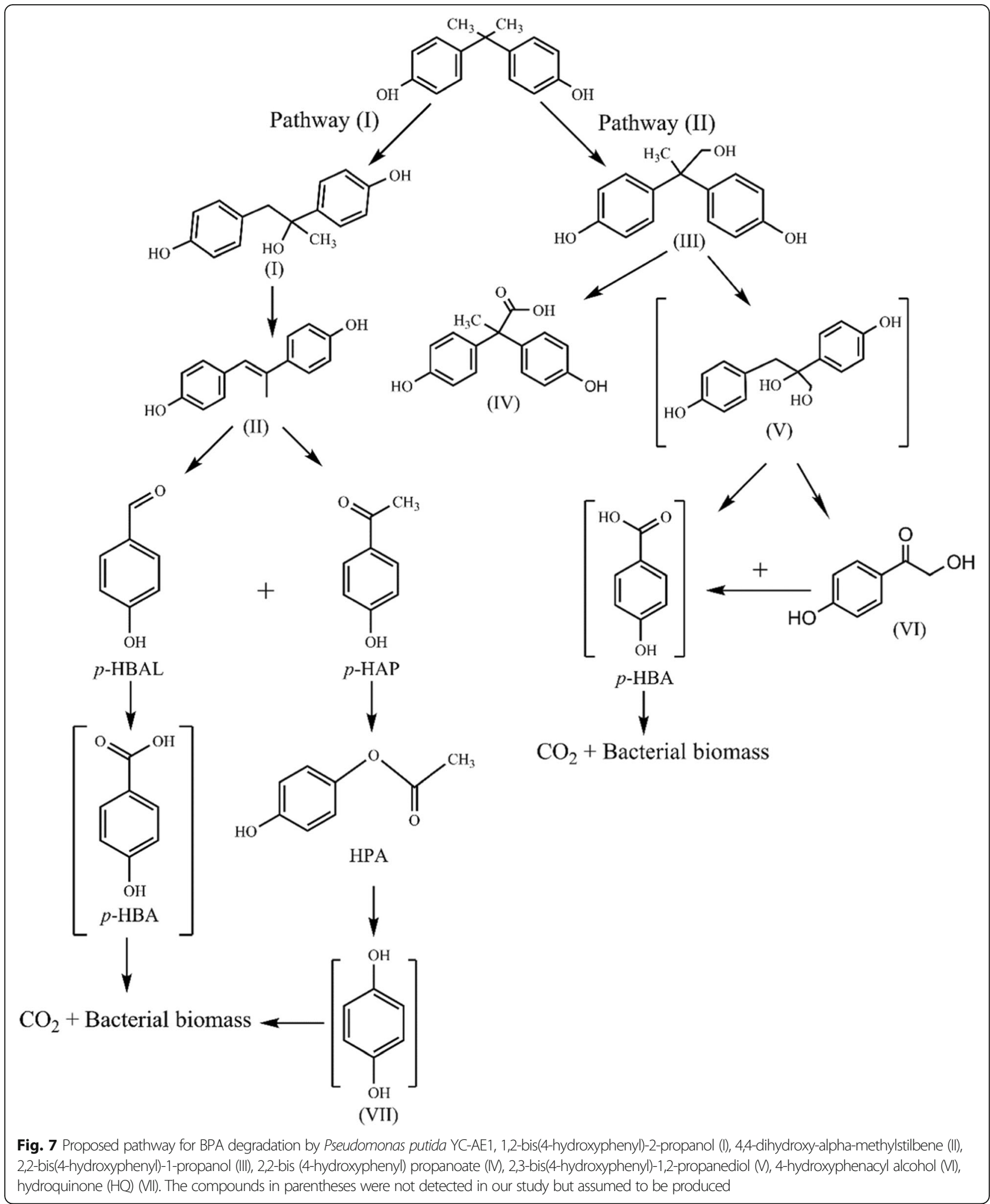

the high degradation and mineralization rate of our strain YC-AE1.

The intermediates detected in our study have a good consistency with those reported by Eio et al. [32]. Das et al. [46] reported many different intermediate compounds detected during BPA degradation by recombinant laccase from Bacillus sp. GZB. Three different pathways were proposed based on three intermediates, 
Hydroxybenzaldeyde, $p$-hydroxybenzoic acid and $p$ hydroquinone (HQ) detected during biodegradation of BPA by Achromobacter xylosoxidans strain B-16 isolated from compost leachate [25]. Based on the intermediates obtained in our study using LC-MS and in light of literature $[25,27,32,46,47]$, two degradation pathway by Pseudomonas putida YC-AE1 was proposed. The intermediates were detected from both two degradation pathways at same experiment and this is an evidence that our strain use both of pathways in the degradation and this may interpret the high degradation rate of YC-AE1.

\section{Conclusion}

This study has reported the ability of promising pseudomonas putida strain YC-AE1 isolated from Guangdong province (China) to degrade BPA as the sole source for carbon with excellent adaptation to a wide range of environmental conditions. This strain can degrade both of extremely high and low concentrations of BPA and mineralize it in a short time compared with reported strains. Furthermore, it can degrade many BPA-related pollutants. Analysis of intermediates showed two degradation pathways for BPA which may interpret the fast degradation rate of our strain. These criteria recommend pseudomonas putida YC-AE1 as a promising strain for natural remediation of environmental pollutant BPA. Also, our study provides a good microbial source for further studies on bacterial BPA degradation metabolism and molecular mechanism responsible for that degradation.

\section{Methods}

\section{Chemicals and medium}

The Bisphenols (BPA, BPB, BPF and BPS), DBP, DEHP and DEP used in this study were purchased from Shanghai Macklin Biochemical Co., Ltd. China, (all purities above $99 \%)$. Stock solutions $\left(20,000 \mathrm{mgl}^{-1}\right)$ of all these substrates were prepared by dissolving each individual in methanol (99\%). Other chemicals used were of analytical reagent grade, all solvents used were high performance liquid chromatography (HPLC) grade. Two types of media were used in this study: (1) Luria-Bertani (LB) medium for growth and enrichment. It consisted of 10.0 $\mathrm{gl}^{-1}$ peptone, $5.0 \mathrm{gl}^{-1}$ yeast extract, and $10.0 \mathrm{gl}^{-1} \mathrm{NaCl}$. (2) Trace Elements Medium (TEM) as described by [48] were used for isolation of BPA biodegradable strains and statistical optimization experiments.

\section{Isolation, screening and culture conditions for high tolerant BPA degrading strain}

Soil and water samples were collected from five different provinces in China and these provinces were Heilongjiang, Hebei, Shandong, Guangdong and Anhui. Five grams or 5 $\mathrm{ml}$ of soil or water samples respectively, were separately added to $100 \mathrm{ml}$ of TEM in $250 \mathrm{ml}$ Erlenmeyer flask and supplied with $100 \mathrm{mgl}^{-1}$ of BPA. The flasks were incubated in a rotary shaker at $30^{\circ} \mathrm{C}$ with $180 \mathrm{rpm}$. After 7 days, $5 \mathrm{ml}$ of the culture (each flask) was transferred to fresh TEM with $200 \mathrm{mgl}^{-1}$ and incubated at the same condition mentioned above for 7 days. This process was repeated three more times with increasing BPA concentrations in each run to reach $500 \mathrm{mgl}^{-1}$ [49]. The final cultures were spread on solid TEM containing $100 \mathrm{mgl}^{-1}$ BPA as a sole source of carbon and incubated for 5 days at $30^{\circ} \mathrm{C}$, single colonies were picked and inoculated into TEM supplemented with $100 \mathrm{mgl}^{-1}$ BPA and incubated $\left(30{ }^{\circ} \mathrm{C}\right.$ and $180 \mathrm{rpm}$ ) to test the biodegradation. Uninoculated fresh culture of TEM with $100 \mathrm{mg} \mathrm{l}^{-1} \mathrm{BPA}$ was set as abiotic control. The residual concentrations of BPA were determined by using HPLC.

\section{Identification of BPA degrading strain}

The total genomic DNA of bacterial isolate was extracted by using Bacterial Genomic Extraction Kit (Takara, Japan). The 16S rRNA gene was amplified from genomic DNA by using two universal primers (27F: AGAGTTTGATCCTG GCTCAG, 1492R: AAGGAGGTGATCCAGCC). The PCR product was sequenced (Sangon Biotech Co., Ltd., Beijing, China) and the obtained sequence was deposited to GenBank, and aligned to get the similar sequences by BLAST (https://blast.ncbi.nlm.nih.gov/Blast.cgi). The phylogenetic tree was constructed using MEGA 5 software [50] with a neighbor-joining algorithm [51]. The tree was drawn to scale, with branch lengths in the same units as those of the evolutionary distances used to infer the phylogenetic tree. The evolutionary distances were computed using the maximum composite likelihood method [52]. To confirm $16 \mathrm{~S}$ rRNA gene identification and determining the biochemical tests of the bacterial isolate, Biolog tests (BIOLOG inc., USA), was accomplished and the results were analyzed by Microlog 3 (version 5.2) software.

\section{Statistical optimization of BPA degradation by response surface methodology (RSM)}

RSM was conducted using a factorial central composite design (CCD). CCD is one of the most common design used in RSM which has the same predictability in all directions from the center [53]. Five experimental factors selected to design the experiment included $\mathrm{pH}(\mathrm{A}), \mathrm{NaCl}$ concentration (B), incubation period $(\mathrm{C})$, inoculum size (D) and incubation temperature (E) with 5 levels for each factor, generating 29 trials using Design-Expert software (version 8). The Reduced Cubic Model was fitted for biodegradation response analysis. The value of the dependent response was the mean of three replications. The detailed experimental designs of five parameters are shown in Table 1. In this experiment, TEM with BPA (200 $\left.\mathrm{mgl}^{-1}\right)$ as sole source of carbon was used and inoculum was prepared by growing the bacterial strain 
on L. B medium to reach $\left(\mathrm{O} \cdot \mathrm{D}_{(600)}=0.8\right)$, the bacterial cells were collected by centrifugation at $5000 \mathrm{rpm}$ for 5 min and washed twice by fresh TEM and resuspended using the same original volume with TEM.

\section{Substrate utilization test}

To determine the ability of selected strain to degrade different organic pollutants other than BPA, the bacterial strain was inoculated (1\% inoculum size) into TEM (15 $\mathrm{ml}$ ) supplemented with $100 \mathrm{mgl}^{-1}$ of each of the following substrates: bisphenol B (BPB), bisphenol $\mathrm{F}$ (BPF), bisphenol S (BPS), Dibutyl phthalate (DBP), Diethylhexyl phthalate (DEHP) and Diethyl phthalate (DEP). The cultures were incubated in a rotary shaker $\left(30^{\circ} \mathrm{C}\right.$ and 180 $\mathrm{rpm})$ for $72 \mathrm{~h}$. Cultures without inoculation were set as abiotic control. The residual concentrations of bisphenols (B, F, and S) and (DBP, DEHP) were measured by HPLC and gas chromatography (GC) respectively.

\section{Detection of intermediates}

To determine the biodegradation intermediates, the selected bacterial strain was grown in TEM supplemented with BPA (200 $\left.\mathrm{mgl}^{-1}\right)$ under optimal culture conditions. $100 \mathrm{ml}$ of sample was taken from the culture at specific intervals as following $(15,20,24,28,32,36 \mathrm{~h})$ and centrifuged at $10000 \mathrm{rpm}$ for $10 \mathrm{~min}$, the cell-free supernatant was acidified ( $\mathrm{pH}: 2-3)$ using $\mathrm{HCl}$. The samples were extracted twice with the same volume of ethyl acetate, organic layer separated and dried by Rotary evaporator (BUCHI, Switzerland) and re-suspended in $1 \mathrm{ml}$ methanol (99\%). The samples were subjected to high performance liquid chromatography-mass spectroscopy (HPLC-MS) to detect the intermediates.

\section{BPA degradation at low and high concentrations and total organic carbon (TOC) determination}

The concentration of BPA in natural polluted environments is very low compared with that always examined in vitro. Therefore, the ability of bacterial strain to degrade and utilize BPA at low and high concentrations is a very important character especially in strains intended to use in environmental bioremediation. The high and low concentrations used were as follows $(50,100,200,300,400$, $500,600,700,800,900$, and $\left.1000 \mathrm{mg} \mathrm{l}^{-1}\right)$ and $(0.5,1,2,4$, $6,8,10$ and $12 \mathrm{mgl}^{-1}$ ) respectively. The residual BPA concentration and degradation rate were determined after 15 and $72 \mathrm{~h}$ for low and high concentrations by HPLC, respectively. In low concentration experiment, the relatively short incubation time was to detect the differences in degradation rates compared with BPA concentrations. To detect the BPA mineralization rate, TOC depletion was determined during the degradation time. The selected bacterial strain was grown in TEM supplemented with $100 \mathrm{mg} \mathrm{l}^{-1}$ of BPA at $30^{\circ} \mathrm{C}$. Samples $(20 \mathrm{ml})$ were taken in triplicate each $8 \mathrm{~h}$ intervals as following $(8,16,24,32,40$, 48,56 and $64 \mathrm{~h}$ ) and centrifugated at $15000 \mathrm{rpm}$ for 30 min to eliminate the bacterial cells. The cell-free supernatant was kept at $-20^{\circ} \mathrm{C}$. TOC was determined for all preserved samples by Walkley-Black method [54].

\section{Analysis methods}

Cell growth was measured as optical density (OD) at $600 \mathrm{~nm}$ using a UV-Visible spectrophotometer (Thermo-Scientific, USA). For detection of bisphenols, an Agilent 1200 system HPLC (Agilent, USA) with visible ultraviolet detector was used equipped with Eclipse XDB C18 column $(4.6 \times 150$ $\mathrm{mm} \times 5 \mu \mathrm{m})$. The mobile phase was acetonitrile $85 \%$ and (water, $0.1 \%$ acetic acid) $15 \%$, with a flow rate $1 \mathrm{ml} /$ minute and detecting wavelength $220 \mathrm{~nm}$. The retention time was $1.55 \mathrm{~min}$ and $2 \mu \mathrm{l}$ for sample injection, the detection limits were $0.3,0.4, .4,0.5{\mu \mathrm{gml}^{-1}}^{-1}$ for BPA, BPB, BPF and BPS, respectively. For detection of DBP, DEHP and DEP, a GC system (GC-2010 SHIMADZU, Kyoto, Japan) with a flame ionizing detector (FID) was used. Samples were extracted twice by an equal volume of $n$-hexane and the hexan phase was separated and analyzed by GC [55], the detection limits were $0.1 \mathrm{\mu gml}^{-1}$. The intermediate metabolites of BPA degradation were analyzed by (HPLC-MS, 1290, USA). The mobile phase was a mixture of (50:50\%) of water and acetonitrile (with $0.1 \%$ formic acid for each one), running at a flow rate of $1 \mathrm{~mL} / \mathrm{min}$. The sample was injected $(2 \mu \mathrm{L})$ as methanolic extract and scan mode with $3 \mathrm{kV}$ capillary voltage was used to analyze negative ionization. The dry gas flow was 5 $\mathrm{L} / \mathrm{min}$ and the dry nitrogen was heated to $325^{\circ} \mathrm{C}$. Mass hunter (version A.02.00, Agilent, USA) was used to analyze and collect the data.

\section{Abbreviations \\ BPA: Bisphenol A; BPB: Bisphenol B; BPF: Bisphenol F; BPS: Bisphenol S; CCD: Central composite design; DBP: Dibutyl phthalate; DEHP: Diethylhexyl phthalate; DEP: Diethyl phthalate; GC: Gas chromatography; \\ HPA: Hydroxyphenylacetate; HPLC: High performance liquid chromatography; HQ: Hydroquinone; $p$-HAP: $p$-hydroxyacetophenone; $p$-HBAL: $p$ - \\ hydroxybenzaldeyde; RSM: Response Surface Methodology; TEM: Trace elements medium; TOC: Total organic acrbon}

\section{Acknowledgments}

We are grateful to Mr. Xianjun Li for his assistance in the collection of samples and Khaled S. Nassar for his helping in designing the experiment with Design Expert software. Also, we thank Ebrahim Shehata for his technical assistance in the TOC experiment.

\section{Authors' contributions}

AE conducted the practical work for all experiments; YJ designed the statistical optimization experiments; JW analyzed the HPLC-MS results. YJ and JW contributed reagents/materials/analysis tools; AE and MAAK wrote the manuscript. NR, IK and YY revised the manuscript. All authors have read and approved the final manuscript.

\section{Funding}

This study is financially supported by National Natural Science Foundation of China [Nos. 31540067, 21876201] and the Basic Research Fund of Chinese Academy of Agricultural Sciences [Nos. 1610042017001, 1610042018005 and 1610042018006]. The funding body has no role in the design of the study and collection, analysis, interpretation of data and in writing the manuscript. 


\section{Availability of data and materials}

All data generated or analyzed during this study are included in this published article except the sequence of 16S rRNA gene was deposited to Gen Bank (NCBI) with accession number, MK318658

\section{Ethics approval and consent to participate}

Sampling was conducted on private lands after taking the permissions from the owners of these lands.

\section{Consent for publication}

Not applicable.

\section{Competing interests}

The authors declare that they have no competing interests.

\section{Author details}

'Graduate School of Chinese Academy of Agricultural Sciences, Beijing 100081, China. ${ }^{2}$ Botany and Microbiology Department, Faculty of Science, AL-Azhar University, Assiut 71524, Egypt. ${ }^{3}$ Institute of Modern Biopharmaceuticals, School of Life Sciences, Southwest University, Chongqing 400715, China.

\section{Received: 24 July 2019 Accepted: 9 January 2020}

Published online: 13 January 2020

\section{References}

1. Atacag EH. Biodegradation and detoxification of BPA: involving laccase and a mediator. CLEAN Soil Air Water. 2015;43:932-9.

2. Wang Q, Chen M, Shan G, Chen P, Cui S, Yi S, et al. Bioaccumulation and biomagnification of emerging bisphenol analogues in aquatic organisms from Taihu Lake, China. Sci Total Environ. 2017;598:814-20.

3. Alexander HC, Dill DC, Smith LW, Guiney PD, Dorn P. Bisphenol A: acute aquatic toxicity. Environ Toxicol Chem. 1988;7:19-26.

4. Seachrist DD, Bonk KW, Ho SM, Prins GS, Soto AM, Keri RA. A review of the carcinogenic potential of bisphenol a. Reprod Toxicol. 2016;59:167-82. https://doi.org/10.1016/j.reprotox.2015.09.006.

5. Welshons WV, Thayer KA, Judy BM, Taylor JA, Curran EM, Vom Saal FS. Large effects from small exposures. I. Mechanisms for endocrinedisrupting chemicals with estrogenic activity. Environ Health Perspect. 2003;111:994-1006.

6. Vom Saal FS, Hughes C. An extensive new literature concerning low-dose effects of bisphenol a shows the need for a new risk assessment. Environ Health Perspect. 2005;113:926-33.

7. Vandenberg LN, Colborn T, Hayes TB, Heindel JJ, Jacobs DR Jr, Lee D-H, et al. Hormones and endocrine-disrupting chemicals: low-dose effects and nonmonotonic dose responses. Endocr Rev. 2012:33:378-455.

8. Kang JH, Kondo F. Bisphenol a in the surface water and freshwater snail collected from rivers around a secure landfill. Bull Environ Contam Toxicol. 2006;76:113-8

9. Ye X, Pierik FH, Angerer J, Meltzer HM, Jaddoe WW, Tiemeier H, et al. Levels of metabolites of organophosphate pesticides, phthalates, and bisphenol a in pooled urine specimens from pregnant women participating in the Norwegian mother and child cohort study (MoBa). Int J Hyg Environ Health. 2009;212:481-91

10. Larsson $\mathrm{K}$, Lindh $\mathrm{CH}$, Jönsson BAG, Giovanoulis G, Bibi M, Bottai M, et al. Phthalates, non-phthalate plasticizers and bisphenols in Swedish preschool dust in relation to children's exposure. Environ Int. 2017:102:114-24.

11. Zhou NA, Kjeldal H, Gough HL, Nielsen JL. Identification of putative genes involved in bisphenol a degradation using differential protein abundance analysis of Sphingobium sp. BiD32. Environ Sci Technol. 2015;49:12232-41.

12. Chouhan S, Yadav SK, Prakash J, Singh SP. Effect of Bisphenol a on human health and its degradation by microorganisms: a review. Ann Microbiol. 2014;64:13-21

13. Yamada H, Furuta I, Kato EH, Kataoka S, Usuki Y, Kobashi G, et al. Maternal serum and amniotic fluid bisphenol a concentrations in the early second trimester. Reprod Toxicol. 2002;16:735-9.

14. Zhang Y, Tao S, Yuan C, Liu Y, Wang Z. Non-monotonic dose-response effect of bisphenol a on rare minnow Gobiocypris rarus ovarian development. Chemosphere. 2016;144:304-11.
15. Chen J, Xiao Y, Gai Z, Li R, Zhu Z, Bai C, et al. Reproductive toxicity of low level bisphenol a exposures in a two-generation zebrafish assay: evidence of male-specific effects. Aquat Toxicol. 2015;169:204-14.

16. Yamamoto T, Yasuhara A, Shiraishi H, Nakasugi O. Bisphenol a in hazardous waste landfill leachates. Chemosphere. 2001;42:415-8.

17. Lee H-B, Peart TE. Bisphenol a contamination in Canadian municipal and industrial wastewater and sludge samples. Water Qual Res J. 2000;35:283-98.

18. Kleywegt S, Pileggi V, Yang P, Hao C, Zhao X, Rocks C, et al. Pharmaceuticals, hormones and bisphenol a in untreated source and finished drinking water in Ontario, Canada_occurrence and treatment efficiency. Sci Total Environ. 2011;409:1481-8.

19. Bolz U, Hagenmaier H, Körner W. Phenolic xenoestrogens in surface water, sediments, and sewage sludge from Baden-Württemberg, south-West Germany. Environ Pollut. 2001;115:291-301.

20. Kolpin DW, Furlong ET, Meyer MT, Thurman EM, Zaugg SD, Barber LB, et al. Pharmaceuticals, hormones, and other organic wastewater contaminants in US streams, 1999-2000: A national reconnaissance. Environ Sci Technol. 2002;36:1202-11.

21. Staples CA, Dome PB, Klecka GM, Oblock ST, Harris LR. A review of the environmental fate, effects, and exposures of bisphenol a. Chemosphere. 1998:36:2149-73.

22. Yamauchi K, Ishihara A, Fukazawa $H$, Terao $Y$. Competitive interactions of chlorinated phenol compounds with 3, 3', 5-triiodothyronine binding to transthyretin: detection of possible thyroid-disrupting chemicals in environmental waste water. Toxicol Appl Pharmacol. 2003:187:110-7.

23. Wang R, Diao P, Chen Q, Wu H, Xu N, Duan S. Identification of novel pathways for biodegradation of bisphenol a by the green alga Desmodesmus sp. WR1, combined with mechanistic analysis at the transcriptome level. Chem Eng J. 2017;321:424-31. https://doi.org/10.1016/j. cej.2017.03.121.

24. Kang J-H, Katayama Y, Kondo F. Biodegradation or metabolism of bisphenol a: from microorganisms to mammals. Toxicology. 2006;217:81-90.

25. Zhang C, Zeng G, Yuan L, Yu J, Li J, Huang G, et al. Aerobic degradation of bisphenol a by Achromobacter xylosoxidans strain B-16 isolated from compost leachate of municipal solid waste. Chemosphere. 2007;68:181-90.

26. Kang $\mathrm{JH}$, Kondo $\mathrm{F}$. Bisphenol a degradation by bacteria isolated from river water. Arch Environ Contam Toxicol. 2002;43:265-9.

27. Suyamud B, Inthorn D, Panyapinyopol B. Biodegradation of Bisphenol a by a newly isolated Bacillus megaterium strain ISO-2 from a polycarbonate industrial wastewater; 2018.

28. Oshiman Kl, Tsutsumi Y, Nishida T, Matsumura Y. Isolation and characterization of a novel bacterium, Sphingomonas bisphenolicum strain AO1, that degrades bisphenol a. Biodegradation. 2007;18:247-55.

29. Xu C-P, Kim S-W, Hwang H-J, Choi J-W, Yun J-W. Optimization of submerged culture conditions for mycelial growth and exo-biopolymer production by Paecilomyces tenuipes C240. Process Biochem. 2003;38:1025-30.

30. Khambhaty Y, Mody K, Jha B, Gohel V. Statistical optimization of medium components for $\mathrm{k}$-carrageenase production by Pseudomonas elongata. Enzym Microb Technol. 2007:40:813-22.

31. Kumar P, Satyanarayana T. Optimization of culture variables for improving glucoamylase production by alginate-entrapped Thermomucor indicaeseudaticae using statistical methods. Bioresour Technol. 2007;98:1252-9.

32. Eio EJ, Kawai M, Tsuchiya K, Yamamoto S, Toda T. Biodegradation of bisphenol a by bacterial consortia. Int Biodeterior Biodegrad. 2014;96:16673. https://doi.org/10.1016/jibiod.2014.09.011.

33. Ren L, Jia Y, Ruth N, Shi Y, Wang J, Qiao C, et al. Biotransformations of bisphenols mediated by a novel Arthrobacter sp. strain YC-RL1. Appl Microbiol Biotechnol. 2016;100:1967-76.

34. Smita GS, Ray P, Mohapatra S. Quantification and optimization of bacterial isolates for production of alkaline protease. Asian J Exp Biol Sci. 2012;3:180-6.

35. Karthikeyan RS, Rakshit SK, Baradarajan A. Optimization of batch fermentation conditions for dextran production. Bioprocess Eng. 1996;15: 247-51.

36. Engqvist MKM. Correlating enzyme annotations with a large set of microbia growth temperatures reveals metabolic adaptations to growth at diverse temperatures. BMC Microbiol. 2018;18:1-14.

37. Fouda A. Biodegradation of Bisphenol a by some bacterial species and significance role of plasmids. Int J Adv Res Biol Sci. 2015;2:93-108.

38. Ulrich AC, Guigard SE, Foght JM, Semple KM, Pooley K, Armstrong JE, et al. Effect of salt on aerobic biodegradation of petroleum hydrocarbons in contaminated groundwater. Biodegradation. 2009;20:27-38. 
39. de Carvalho CC, da Fonseca MM. Degradation of hydrocarbons and alcohols at different temperatures and salinities by Rhodococcus erythropolis DCL14. FEMS Microbiol Ecol. 2005;51:389-99.

40. Basha KM, Rajendran A, Thangavelu V. Recent advances in the biodegradation of phenol: a review. Asian J Exp Biol Sci. 2010;1:219-34.

41. Lee SG, Yoon BD, Park YH, Oh HM. Isolation of a novel pentachlorophenoldegrading bacterium, Pseudomonas sp. Bu34. J Appl Microbiol. 1998;85:1-8.

42. Kumar A, Kumar S, Kumar S. Biodegradation kinetics of phenol and catechol using Pseudomonas putida MTCC 1194. Biochem Eng J. 2005;22:151-9.

43. Peng X, Qu X, Luo W, Jia X. Co-metabolic degradation of tetrabromobisphenol a by novel strains of Pseudomonas sp. and Streptococcus sp. Bioresour Technol. 2014;169:271-6.

44. Yamada T, Takahama Y, Yamada Y. Biodegradation of 2, 4, 6-tribromophenol by Ochrobactrum sp. strain TB01. Biosci Biotechnol Biochem. 2008;72:1264-71.

45. Yu K, Yi S, Li B, Guo F, Peng X, Wang Z, et al. An integrated meta-omics approach reveals substrates involved in synergistic interactions in a bisphenol a (BPA)-degrading microbial community. Microbiome. 2019;7:1-13.

46. Das R, Li G, Mai B, An T. Spore cells from BPA degrading bacteria Bacillus sp. GZB displaying high laccase activity and stability for BPA degradation. Sci Total Environ. 2018;640-641:798-806. https://doi.org/10.1016/j.scitotenv. 2018.05.379.

47. Wang J, Ren L, Jia Y, Ruth N, Shi Y, Qiao C, et al. Degradation characteristics and metabolic pathway of 4-nitrophenol by a halotolerant bacterium Arthrobacter sp. CN2. Toxicol Environ Chem. 2016;98:226-40.

48. Nahurira R, Ren L, Song J, Jia Y, Wang J, Fan S, et al. Degradation of Di(2Ethylhexyl) phthalate by a novel Gordonia alkanivorans strain YC-RL2. Curr Microbiol. 2017;74:309-19.

49. Ren L, Jia Y, Ruth N, Qiao C, Wang J, Zhao B, et al. Biodegradation of phthalic acid esters by a newly isolated Mycobacterium sp. YC-RL4 and the bioprocess with environmental samples. Environ Sci Pollut Res. 2016;23: 16609-19. https://doi.org/10.1007/s1 1356-016-6829-4.

50. Tamura K, Peterson D, Peterson N, Stecher G, Nei M, Kumar S. MEGA5: molecular evolutionary genetics analysis using maximum likelihood, evolutionary distance, and maximum parsimony methods. Mol Biol Evol. 2011:28:2731-9.

51. Saitou N, Nei M. The neighbor-joining method: a new method for reconstructing phylogenetic trees. Mol Biol Evol. 1987:4:406-25.

52. Tamura K, Nei M, Kumar S. Prospects for inferring very large phylogenies by using the neighbor-joining method. Proc Natl Acad Sci. 2004:101:11030-5.

53. Gao Y-L, Ju X-R, Jiang H-H. Use of response surface methodology to investigate the effect of food constituents on Staphylococcus aureus inactivation by high pressure and mild heat. Process Biochem. 2006;41:362-9.

54. Walkley A, Black IA. An examination of the Degtjareff method for determining soil organic matter, and a proposed modification of the chromic acid titration method. Soil Sci. 1934;37:29-38.

55. Zhang Y, Chen H, Liu J, Geng G, Liu D, Geng H, et al. Genome sequencing and biodegradation characteristics of the $n$-butyl benzyl phthalate degrading rdthetghteyt/Im ;n HS-D2 rdthetghteyt. Int Biodeterior Biodegradation. 2016;128:56-62.

\section{Publisher's Note}

Springer Nature remains neutral with regard to jurisdictional claims in published maps and institutional affiliations.

Ready to submit your research? Choose BMC and benefit from:

- fast, convenient online submission

- thorough peer review by experienced researchers in your field

- rapid publication on acceptance

- support for research data, including large and complex data types

- gold Open Access which fosters wider collaboration and increased citations

- maximum visibility for your research: over $100 \mathrm{M}$ website views per year

At $\mathrm{BMC}$, research is always in progress.

Learn more biomedcentral.com/submissions 